\title{
Discrimination of Solid from Liquid Precipitation over Northern Eurasia Using Surface Atmospheric Conditions*
}

\author{
HENGCHUN YE \\ Department of Geosciences and Environment, California State University, Los Angeles, Los Angeles, California \\ JUDAH COHEN \\ Atmospheric and Environment Research, Lexington, Massachusetts \\ MichaEL RAWLinS \\ Climate System Research Center, Department of Geosciences, University of Massachusetts Amherst, Amherst, Massachusetts
}

(Manuscript received 13 November 2012, in final form 5 May 2013)

\begin{abstract}
Daily synoptic observations were examined to determine the critical air temperatures and dewpoints that separate solid versus liquid precipitation for the fall and spring seasons at 547 stations over northern Eurasia. The authors found that critical air temperatures are highly geographically dependent, ranging from $-1.0^{\circ}$ to $2.5^{\circ} \mathrm{C}$, with the majority of stations over European Russia ranging from $0.5^{\circ}$ to $1.0^{\circ} \mathrm{C}$ and those over southcentral Siberia ranging from $1.5^{\circ}$ to $2.5^{\circ} \mathrm{C}$. The fall season has a $0.5^{\circ}-1.0^{\circ} \mathrm{C}$ lower value than the spring season at $42 \%$ stations. Relative humidity, elevation, the station's air pressure, and climate regime were found to have varying degrees of influences on the distribution of critical air temperature, although the relationships are very complex and cannot be formulated into a simple rule that can be applied universally. Although the critical dewpoint temperatures have a spread of $-1.5^{\circ}$ to $1.5^{\circ} \mathrm{C}, 92 \%$ of stations have critical values of $0.5^{\circ}-$ $1.0^{\circ} \mathrm{C}$. The critical dewpoint is less dependent on environmental factors and seasons. A combination of three critical dewpoints and three air temperatures is developed for each station for spring and fall separately that has improved snow event predictability when the dewpoint is in the range of $-0.5^{\circ}-1.5^{\circ} \mathrm{C}$ and has improved rainfall event predictability when the dewpoint is higher than or equal to $0^{\circ} \mathrm{C}$ based on the statistics of all 537 stations. Results suggest that application of site-specific critical values of air temperature and dewpoint to discriminate between solid and liquid precipitation is needed to improve snow and hydrological modeling at local and regional scales.
\end{abstract}

\section{Introduction}

Precipitation is the most important water resource for the land surface. In high-latitude/high-elevation regions, solid precipitation consists of a very significant portion of total precipitation amount, and its accumulation has a profound influence on surface energy budgets,

\footnotetext{
* Supplemental information related to this paper is available at the Journals Online website: http://dx.doi.org/10.1175/JHM-D12-0164.s1.

Corresponding author address: Hengchun Ye, Department of Geosciences and Environment, California State University, Los Angeles, 5151 State University Dr., Los Angeles, CA 90032.

E-mail: hye2@calstatela.edu
}

hydrological cycles, permafrost condition, surface air temperature, atmospheric circulation, etc. At middle and high latitudes, where most precipitation starts in solid form, the type of precipitation that reaches the ground is determined by the atmospheric condition through which the snowflakes fall. The most common method to separate solid versus liquid precipitation involves surface air temperature, which is the most easily obtained measurement.

In 1974, Auer studied 1000 U.S. Service A Teletype surface weather observations to identify surface air conditions associated with snow and rain. He concluded that when the air temperature is $2.2^{\circ} \mathrm{C}$, the probability of rain and snow are $50 \%$ each, and that $95 \%$ probability for snow occurs at $1.1^{\circ} \mathrm{C}$ and for rain at $5.6^{\circ} \mathrm{C}$. He also stated that rain was virtually never recorded when the 
air temperature was below $0^{\circ} \mathrm{C}$ and that snow was never observed when temperature exceeded $6.1^{\circ} \mathrm{C}$. A recent study by Dai (2008) using global synoptic observations estimated that the half point of snow versus rain over the global land surface is $1.2^{\circ} \mathrm{C}$ and over the oceans is $1.9^{\circ} \mathrm{C}$, and the range of transition is very wide $\left(-2^{\circ}\right.$ to $4^{\circ} \mathrm{C}$ over low and moderately low land). Both studies combined all available station records to derive a single set of critical temperatures that can be applied to all localities over a large study region and over the ocean for all years.

In reality, the atmospheric condition that separates solid versus liquid can vary greatly from one place to another. For example, a study in Japan suggested that critical temperature differences are up to $3^{\circ} \mathrm{C}$ between different locations (Motoyama 1990). Rohrer (1989) found that change in the measurement site resulted in significant change of the mean and the spread of the transition range of air temperature. This may explain the large differences (about $1.0^{\circ} \mathrm{C}$ ) in the critical air temperature $(\mathrm{CT})$ of the half point (50\% of snow and rain) revealed in the studies of Auer (1974) over the United States and Dai (2008) over the global land area and oceans. The Kienzle (2008) study of 15 stations across southwestern Alberta, Canada, revealed a large spread of half-point temperature, ranging from $1.2^{\circ}$ to $4.5^{\circ} \mathrm{C}$ of daily mean. Kienzle (2008) used daily mean temperature, which may increase the range of the difference compared to higher-temporal-resolution measurements other studies used (Rohrer 1989). Yang et al.'s (1997) modeling study at five stations over Siberia found that lowering critical temperature to $0^{\circ}$ from $2.2^{\circ} \mathrm{C}$ improved the snow accumulation calculation significantly, suggesting a possibly lower critical temperature in Siberia.

In addition to air temperature, other variables that can influence precipitation types include humidity, because of its evaporating role in cooling (Matsuo et al. 1981; Motoyama 1990); air density/pressure that affects the falling speed of each snow flake (Stull 2000; U.S. Army Corps of Engineers 1956); salt content in droplets that reduce freezing point (Dai 2008); elevation that affects the thickness of the air layer through which a snow flake travels; and topography that influences direct solar heating of the ground. Most of these factors are not dominant ones, but they do influence CT values to varying extents and with varying degrees of complexity.

The near-surface vertical temperature profile is also critical to precipitation type. The strong inversion layer found in the Arctic may make it possible for rain to occur even at a very low surface air temperature (Serreze et al. 1992; Bradley et al. 1992). In the Swiss Alps, Rohrer (1989) found that rain occurred with a surface air temperature of $-5.8^{\circ} \mathrm{C}$ because of the presence of a strong inversion and high elevation. The Alberta, Canada, study by Kienzle (2008) found a strong seasonal oscillation in critical temperature with a maximum in winter and a minimum in summer. Insignificant differences in seasonality of critical temperature were found in the study of Dai (2008) in which the entire global land areas were combined without discriminating between regional differences.

The large diversity in CTs on the transition of snow to rain found in different regions and the uncertainty about the potential significance of dewpoint temperature present a need for more comprehensive studies over a large geographical region with very fine spatial resolution. Northern Eurasia is ideal because of its high frequency in snow events, the sheer size of the subarctic landmass, the good quality of historical synoptic observations, and the significant role of Eurasian snow cover to the global climate system (Cohen and Entekhabi 1999).

We investigate critical surface air temperature and dewpoint for individual stations across northern Eurasia for the spring (March-June, to include some snow events in June in northern regions) and fall (SeptemberNovember) seasons. Dewpoint temperature is directly related to atmospheric humidity, the second-most significant factor in determining precipitation type (Matsuo et al. 1981), and it may have a more consistent critical value for mountain stations (Marks and Winstral 2007). The winter season is excluded from this study because of the fact that liquid precipitation events are mostly limited to European Russia; the rest of the region is predominantly solid precipitation during winter (Ye et al. 2008). Similarly, summer season is excluded from this study because of its small sample size: the average last snowfall date for the coldest stations is 9 June (Ye 2003). The critical value is defined as the half point in precipitation state (50\% solid and $50 \%$ liquid). This half-point value is the most important number for estimating annual snow accumulation based on sensitivity tests in Canada (Kienzle 2008). In addition, most precipitation is a single event of either solid or liquid (Dai 2008) rather than a mixture of both in different proportions depending on air temperatures, an assumption made in many climate models. Detailed station-by-station information is important for smallscale regional hydrological models to better understand local snow accumulation and hydrological processes. This will reveal the geographical and seasonal differences in atmospheric conditions that determine precipitation type. Finally, the potential changes of the ratio of snow to total precipitation will be examined to better understand potential changes in frequencies of precipitation forms under a warming climate (Ye 2008). 


\section{Data and methodology}

The dataset used is the Global Synoptic Climatology Network, C: The former USSR, available from the National Climatic Data Center (NCDC 2005). It is the compilation of in situ hourly meteorological observations for the former Soviet Union. Although some stations go back as early as 1871 , there were only three daily observations before 1936 and four daily observations from 1936 to 1965 based on mean astronomic times, and eight daily observations since January 1966 based on local standard times. There were also many inconsistencies in observation times among stations before 1966. This dataset includes 2095 stations. However, only 757 stations have continued observation through January 2001 because of significant drops in station operation from 1990 to 1993. For this study we chose the time period from 1966 to 2000 because of more consistent observational practices. Among these 757 stations, 547 stations are retained for this study, having record lengths ranging from 27 to 35 years.

The synoptic observation records include sea level pressure, station pressure, air temperature, vapor pressure, relative humidity, wind speed, wind direction, cloud cover and type, and weather condition. The weather condition has codes to indicate many varieties of precipitation types. In this study, we focus only on liquid and solid precipitation. Liquid precipitation includes drizzle, rain, shower, freezing rain and freezing drizzle, and thunderstorm with liquid products; solid precipitation includes snow, snow shower, ice pellets, snow grain, and diamond dust. These groupings are the same as those used in an earlier study examining changes in precipitation types (Ye 2008). The very small number of mixed precipitation events is excluded in analyses. There is a potential problem with weather code " 0 ," which supposedly indicates no weather; there is the possibility that missing values in weather code are also labeled as 0 (NCDC 2005). Since it is very hard to distinguish missing weather observations from no weather condition, we use the air temperature observation as a safeguard. If the air temperature value is labeled as missing and the weather code is 0 , we assume that the accompanying weather code 0 is a missing value at that observation time. Because these observations were made manually, if the person was not able to make it to the station to do a reading of air temperature, it is most likely that he or she would not have been able to record the weather condition either.

Since the original dataset does not include dewpoint temperature, which is also an important variable that closely corresponds to precipitation type based on our earlier exploratory research with a different dataset, the dewpoint temperature is derived from air temperature and relative humidity based on the Magnus formula:

$$
\begin{aligned}
\mathrm{Td} & =c r /(b-r), \\
r & =\ln (\mathrm{RH} / 100)+b T /(c+T),
\end{aligned}
$$

where $T$ is air temperature in degrees Celsius, $\mathrm{RH}$ is relative humidity in percentage, $b=17.67$, and $c=$ $243.5^{\circ} \mathrm{C}$ (Bolton 1980). Ironically, the original NCDC data description document indicates that many of the relative humidity and vapor pressure measurements were converted from dewpoint temperature that has a precision of a whole degree; thus, there could be some range of error in the accuracy of $3 \%$ and $4 \mathrm{hPa}$, respectively (NCDC 2005). The conversion back to dewpoint generates decimals; thus, a small range of possible errors in the dewpoint conversion is expected.

Each liquid and solid event is counted according to each half-degree interval from $-3.5^{\circ}$ to $3.5^{\circ} \mathrm{C}$ for both air temperature and dewpoint at each station. The frequency distribution for rain and snow is constructed across this temperature range as illustrated in Fig. 1a. As air temperature increases, snow frequency decreases while rain frequency increases. At the crossing point where snow frequency drops below $50 \%$ and rain frequency rises above $50 \%$, the $\mathrm{CT}$ for the snow-to-rain transition is thus determined. In a similar way, the critical dewpoint is also estimated for each station (Fig. 1b).

The mean values of relative humidity, air pressure, dewpoint, and air temperature at each station are derived from all observations during the study period. If more than $10 \%$ of observations are missing, that variable is considered as missing for the month and is thus missing for the season. However, if the desired quantity is the climatology value for a station, regardless of the time or year, the mean value is derived from all available observations.

\section{Results}

\section{a. Critical air temperatures}

The CT for all fall (September-November) and spring (March-June) months ranges from $-1.0^{\circ}$ (only at one station) to $2.5^{\circ} \mathrm{C}$, with $85 \%$ of all the stations having an observed $\mathrm{CT}$ of $1.0^{\circ}$ (285 stations) and $1.5^{\circ} \mathrm{C}(180$ stations). The distribution of CT is shown in Fig. 2. The salient features are the lower CTs over European Russia, the highest CTs over southern central Siberia near Lake Baikal, and the moderate CTs in eastern Siberia. Central Siberia is where the elevation starts to rise associated with the high topography of central Asia. To examine if elevation is a factor for increased $\mathrm{CT}$, the 

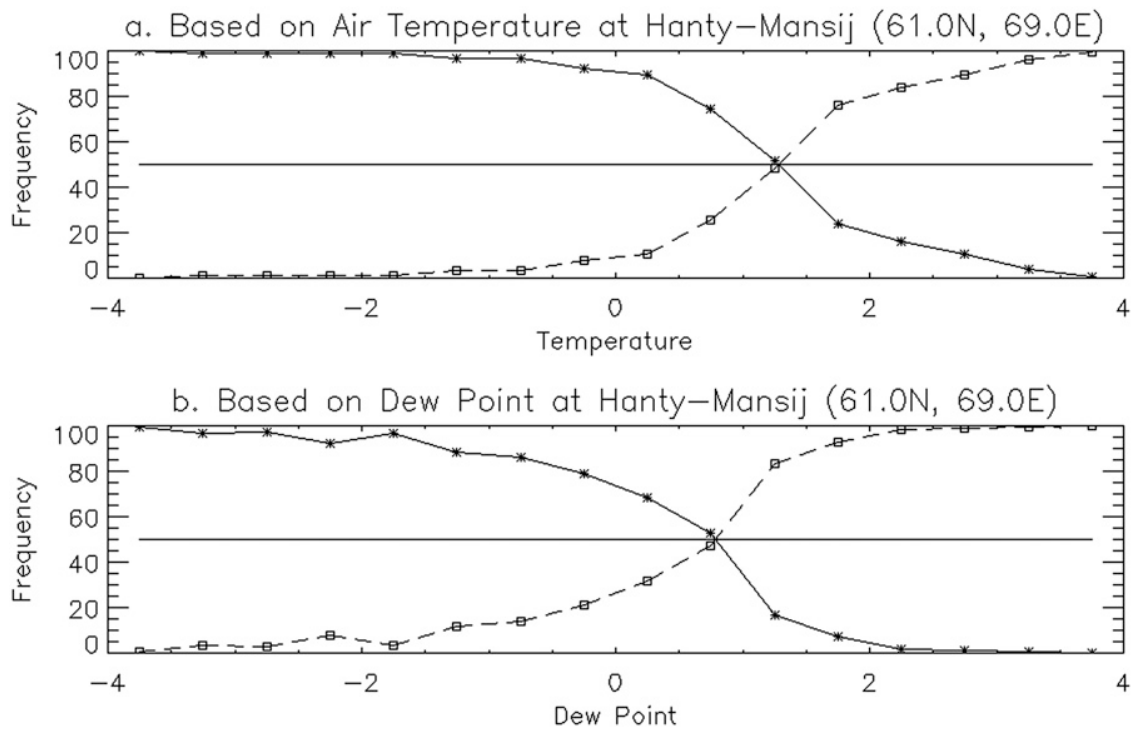

FIG. 1. Frequency distribution of solid (*) and liquid $(\square)$ corresponding to each half-degree increments in (a) air temperature and (b) dewpoint temperature for a randomly selected station (Hanty-Mansij, $61.0^{\circ} \mathrm{N}, 69.0^{\circ} \mathrm{E}$ ). Horizontal line is the $50 \%$ frequency.

scatterplot of CT versus the station's elevation is shown in Fig. 3. No stations at sea level have CTs higher than $1.5^{\circ} \mathrm{C}$, but the highest elevation is not associated with the highest CT. In other words, the very high elevation stations can have very low CTs, and the highest CTs occur in the midrange of elevation, around 400-500 m (Fig. 3). This indicates that elevation is not the only determinant of CT, although the correlation coefficient between elevation and CT is 0.3142 , which is significant at a $99 \%$ confidence level (for the sample size of 547 stations). This complex relationship between critical temperatures and elevation was consistent with the findings by Kienzle (2008) in Alberta, Canada, and by Feiccabrino and Lundberg (2008) in Sweden. Thus, we cannot just use one simple rule to adjust the CT with varying elevations even at nearby stations.

The location of these high CT stations is mostly in a climate regime of Dwc (dry, cold) compared to Dfs (Dfb, Dfc, Dfd; fairly humid, cold) over the rest of the study region based on Köppen's classification. To examine the impact of relative humidity on CT, the scatterplot of CTs and relative humidity are shown in Fig. 4.

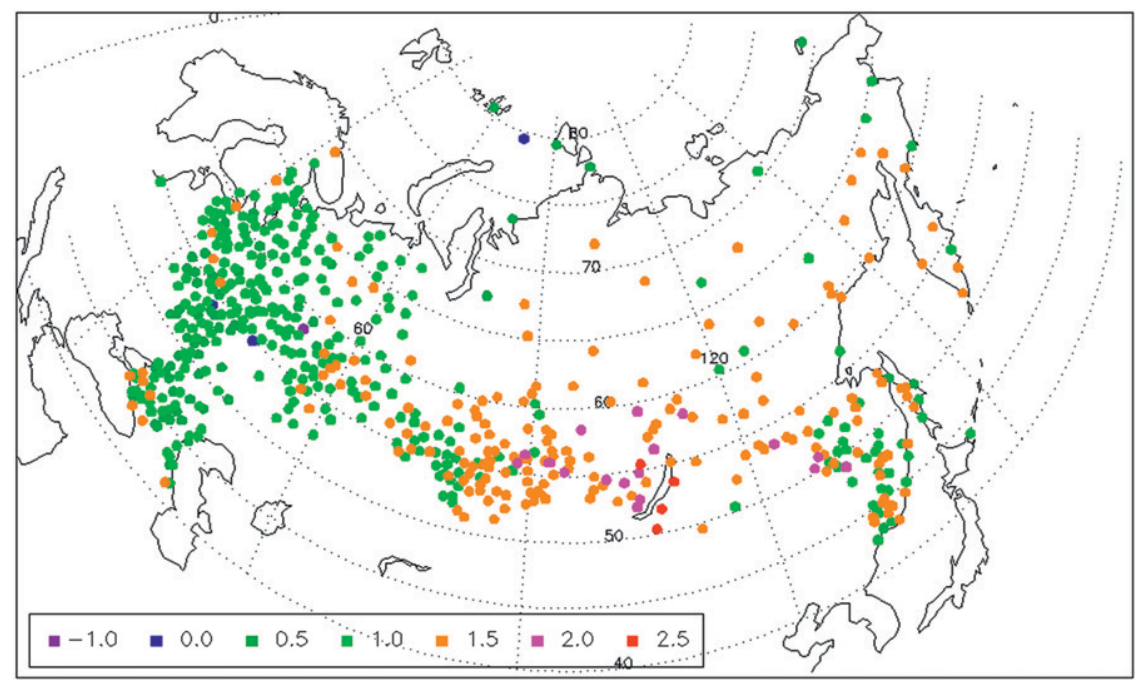

FIG. 2. CT distribution map for all 547 stations and all days in March-June and September-November. 


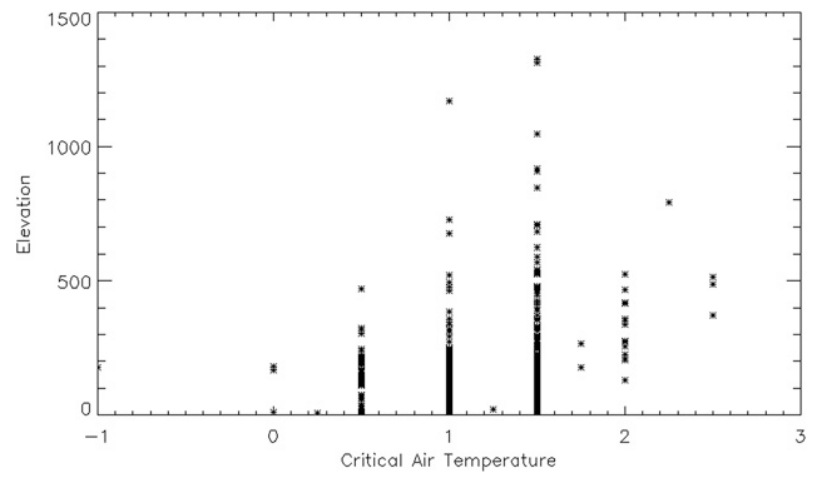

FIG. 3. CTs plotted against the stations' elevations.

In general, the higher CTs are found at stations with lower relative humidity and lower CT stations are associated with higher relative humidity. This is consistent with other studies that suggest snow is more likely to occur at higher air temperature conditions when the air is dry (Matsuo et al. 1981; Motoyama 1990). The correlation coefficient between the two is -0.4087 (sample size of 547 stations), which is statistically significant at the $99 \%$ level and above.

The combined effects of elevation and relative humidity on CT are shown in Fig. 5. Stations with low CTs are located at low elevations and have higher relative humidity while high CTs are found at stations with lower relative humidity and higher elevations. However, the overall separation is not strong.

To further understand how atmospheric conditions alone might impact $\mathrm{CT}$, the data are separated into spring (March-May) and fall (September-November) seasons, and the CT for each season is calculated independently. Any difference in CT is dependent on the atmospheric condition since the geographical features are the same for each station. The map of CT difference between fall and spring (fall CT minus spring CT) shows that 231 stations have a $0.5^{\circ}-1^{\circ} \mathrm{C}$ lower $\mathrm{CT}$ in the fall, 285 stations have no difference, and only 31 stations show that the fall has a higher CT than that of spring (Fig. 6). There is no distinct geographical pattern in the difference of CT between the two seasons, except that large positive numbers (a very small percentage of stations) are mostly found along the southeastern coastal and island stations.

An example of a shift in CT between fall and spring is shown in Fig. 7 at a randomly selected station in European Russia (Hanty-Mansij at $61.0^{\circ} \mathrm{N}, 69.0^{\circ} \mathrm{E}$ ). The potential contributors to the CT difference may be the station's relative humidity and air pressure. Differences in $\mathrm{CT}$ between fall and spring are plotted against differences in relative humidity and air pressure in Fig. 8 . The fall season has a higher relative humidity and higher

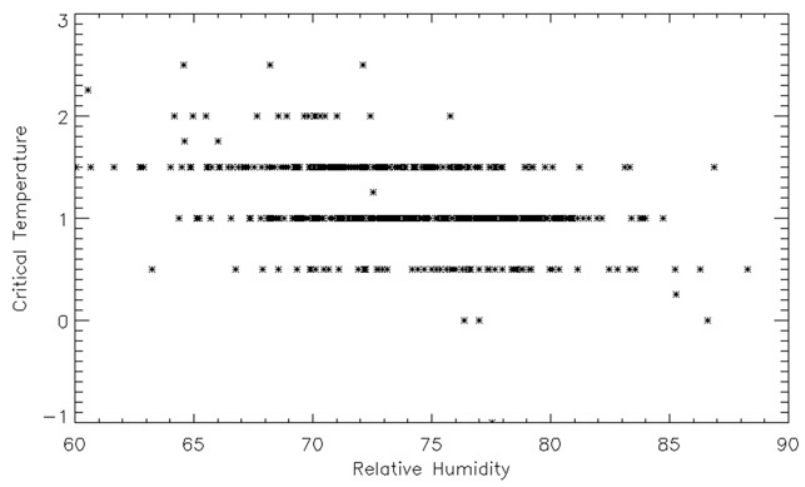

FIG. 4. CTs plotted against the stations' relative humidity.

air pressure at most stations. As a result, fall tends to have a lower CT compared to that of spring. Higher relative humidity tends to reduce critical temperature, while high air pressure associated with high air density decreases the falling speed of snowflakes and provides more time for melting, thus reducing critical temperature. The eastern coastal stations that have higher fall CTs tend to have lower relative humidity in fall (shown in red and orange stars).

\section{b. Critical dew point temperatures}

The critical dewpoint temperature (CTd) ranges from $-1.5^{\circ}$ to $1.0^{\circ} \mathrm{C}$, with 396 stations having $0.5^{\circ} \mathrm{C}$ and 108 stations having $1.0^{\circ} \mathrm{C}$ (accounting for $92.1 \%$ of all stations; see Fig. 9). There is no distinct geographical distribution pattern of critical dewpoint temperature, suggesting that the critical values of dewpoint are less sensitive to local geographical features. Furthermore, differences in critical dewpoint between fall and spring are much less clear: 373 stations show no difference, 75 stations show fall has slightly lower critical temperature, and 99 stations show fall has slightly higher critical

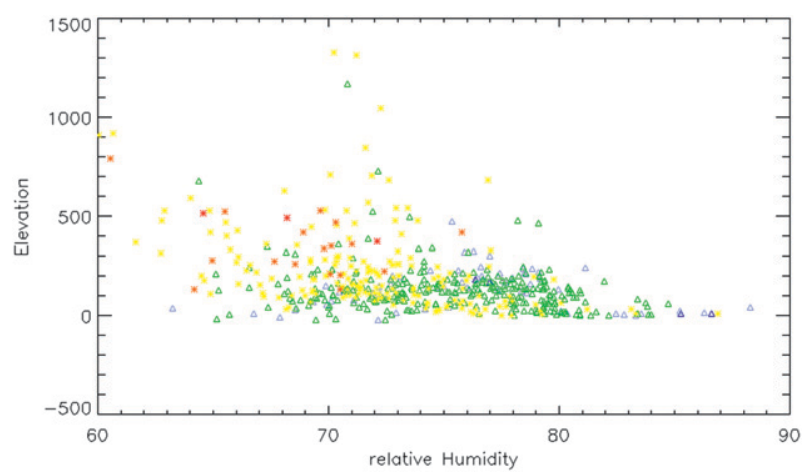

FIG. 5. CT in relation to relative humidity and elevation. Red stars are $2.5^{\circ} \mathrm{C}$, orange stars are $2.0^{\circ} \mathrm{C}$, yellow stars are $2^{\circ} \mathrm{C}$, green triangles are $1.5^{\circ} \mathrm{C}$, light blue triangles are $1^{\circ} \mathrm{C}$, blue triangles are $0.5^{\circ} \mathrm{C}$, and purple triangles are $-0.5^{\circ} \mathrm{C}$ or lower. 


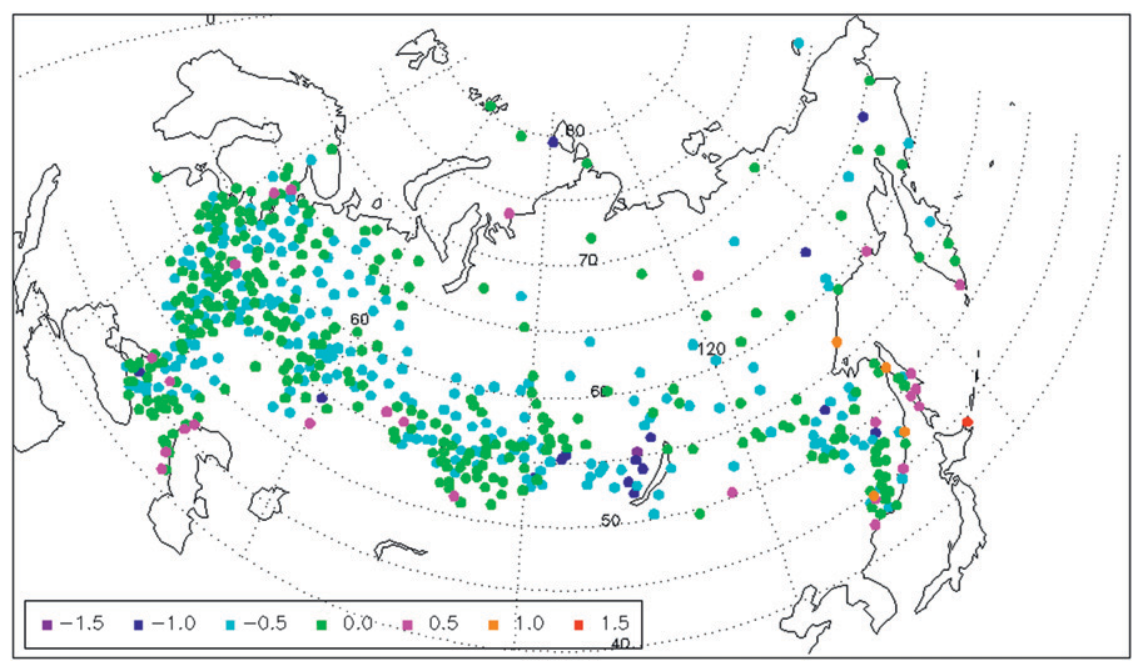

FIG. 6. Differences of CTs between fall (September-November) and spring (March-May) (fall minus spring).

temperature $\left(0.5^{\circ}-1.0^{\circ} \mathrm{C}\right)$. Also, critical dewpoint seems to be insensitive to relative humidity and elevation. Stations with lower CTd appear more likely to have higher station pressure, but there are many exceptions with no clear relationship. This indicates that dewpoint temperature may be a better variable to use in separating solid from liquid precipitation because it seems to be less sensitive to environmental factors. Marks and Winstral (2007), in their study to identify the air temperature and dewpoint when snow changed to rain during major storm events over the Owyhee Mountains of Idaho (1488-1868-m elevation), pointed out this consistency in critical dewpoint temperature.

\section{c. Combination of critical air temperatures and dew points}

The plot of solid and liquid precipitation against corresponding temperature and dewpoint at a range of $-3.5^{\circ} \mathrm{C}$ to $3.5^{\circ} \mathrm{C}$ is shown at a randomly selected station (Ulan-Ude at $51.8^{\circ} \mathrm{N}, 107.43^{\circ} \mathrm{E}$; Fig. 10 ). The combination of critical temperature and dewpoint do a better job of separating solid from liquid precipitation than using just temperature or dewpoint alone. The most clear results are that solid precipitation is dominant when air temperature is lower than or equal to CT and dewpoint is lower than or equal to CTd (lower-left section) and that

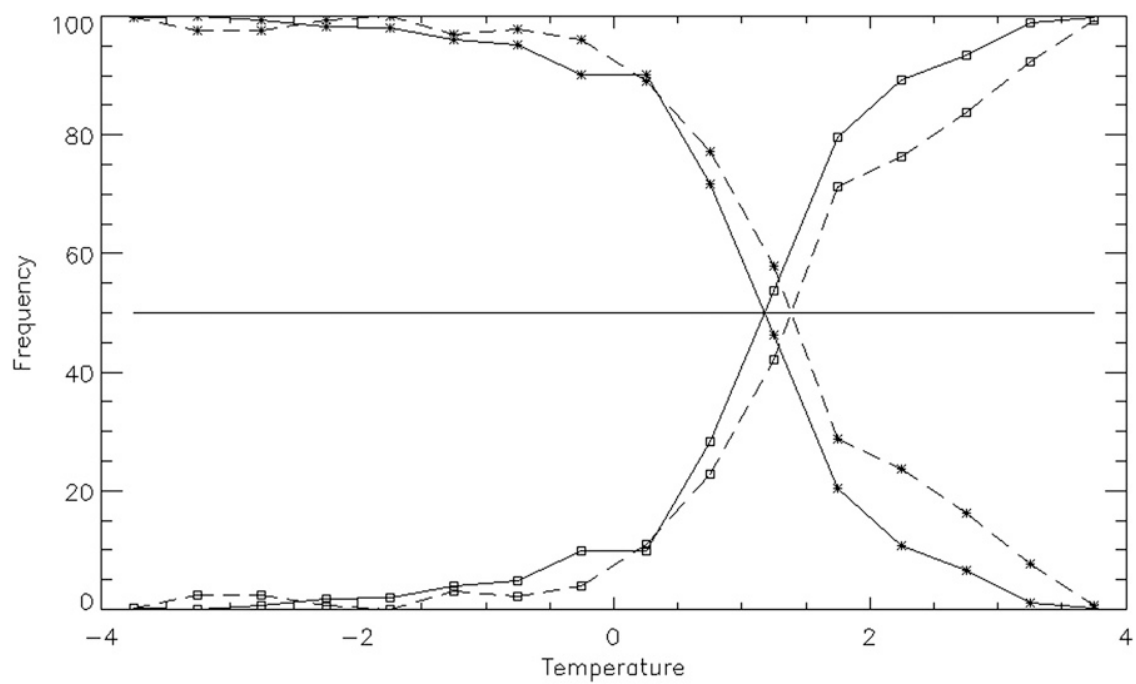

FIG. 7. Frequency distribution of solid (solid lines) and liquid (dashed lines) precipitation for all (solid lines) and spring (dashed line) corresponding to each $0.5^{\circ} \mathrm{C}$ increment in air temperature. Horizontal line is the $50 \%$ frequency. 


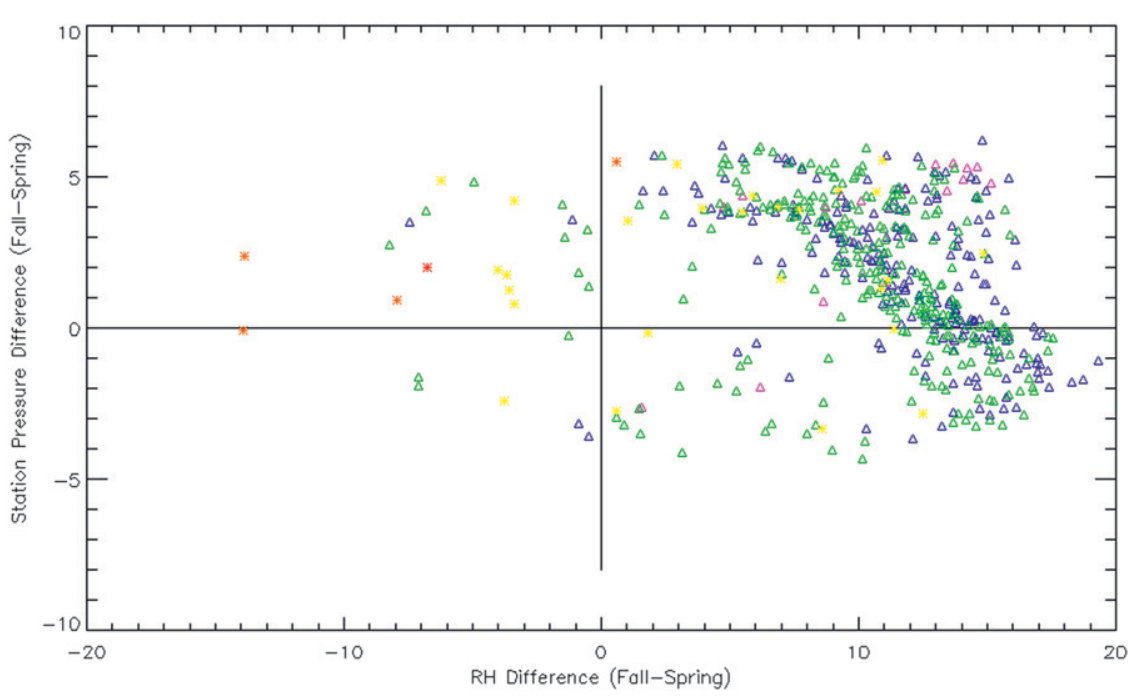

FIG. 8. Difference of CT between fall and spring in relation to the stations' relative humidity and air pressure. Red stars are $1.5^{\circ} \mathrm{C}$, orange stars are $1.0^{\circ} \mathrm{C}$, yellow stars are $0.5^{\circ} \mathrm{C}$, green triangles are $0^{\circ} \mathrm{C}$, blue triangles are $-0.5^{\circ} \mathrm{C}$, purple triangles are $-1.0^{\circ} \mathrm{C}$ or lower.

liquid precipitation is dominant when air temperature is higher than CT and dewpoint is higher than CTd (upperright section). There are still some mixes of both precipitation types at other combinations of temperature and dewpoint (upper-left section and lower-right section). Although the number of events falling into these combinations are not as large as those clearly defined for snow and rain events (especially the upper-left section), there seems to be a pattern. For example, when the dewpoint is lower than CTd (lower-right section of Fig. $10)$, solid precipitation is more likely when air temperature is low; when the dewpoint is higher than CTd (upper-left section), liquid precipitation is more likely when temperature is high (Fig. 10).

To further improve the classification of solid versus liquid precipitation based on these two sections where both could occur, a secondary critical dewpoint and air temperature can be derived by using similar methods, but with a set of limited range of dewpoint and air temperature specific for each of these two sections. For the upper-left section of air temperature less than or equal to CT and dewpoint greater than CTd, the secondary critical dewpoint is the cross point where solid precipitation frequency falls below $50 \%$ and liquid precipitation

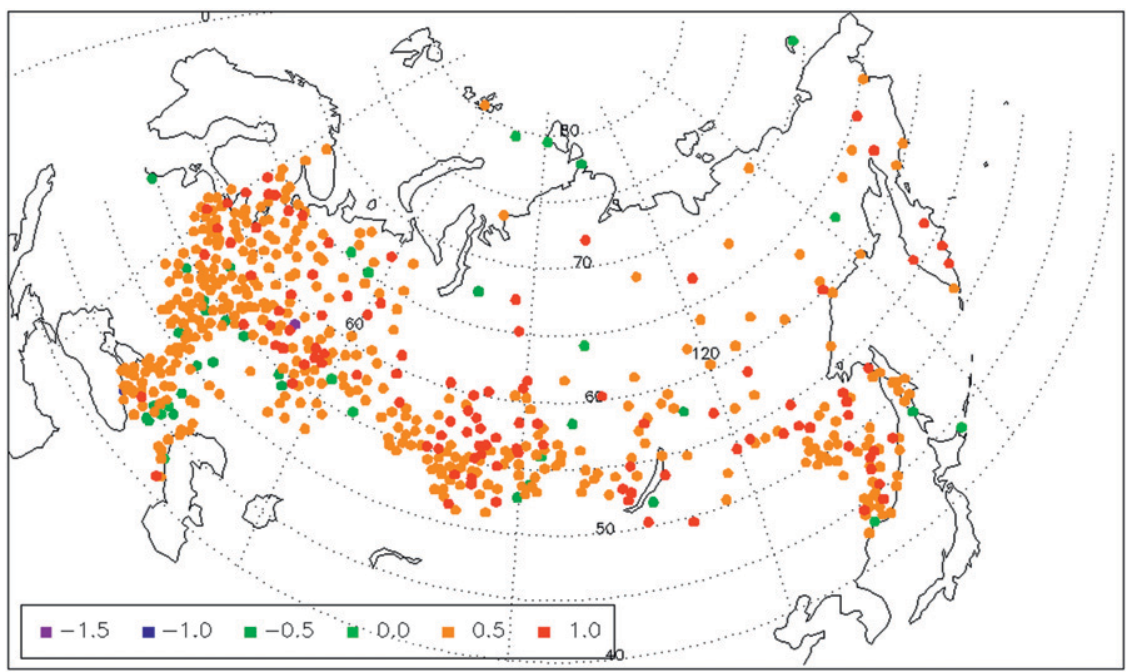

FIG. 9. CTd distribution map for all 547 stations and all days in March-June and September-November. 
a. Fall

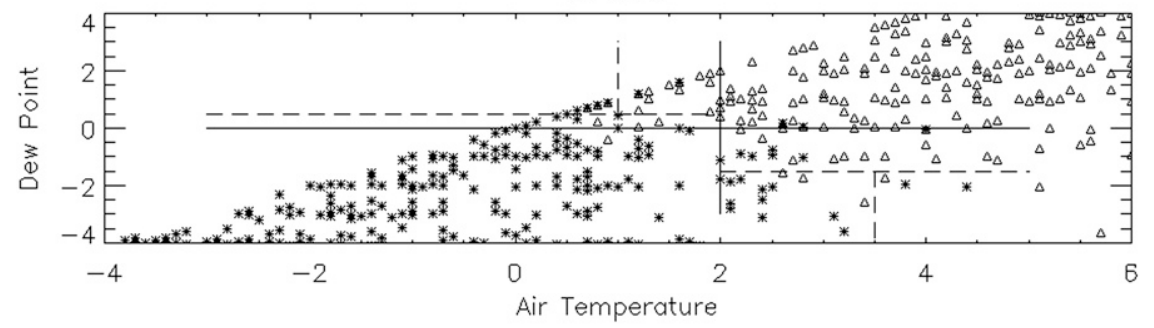

b. Spring

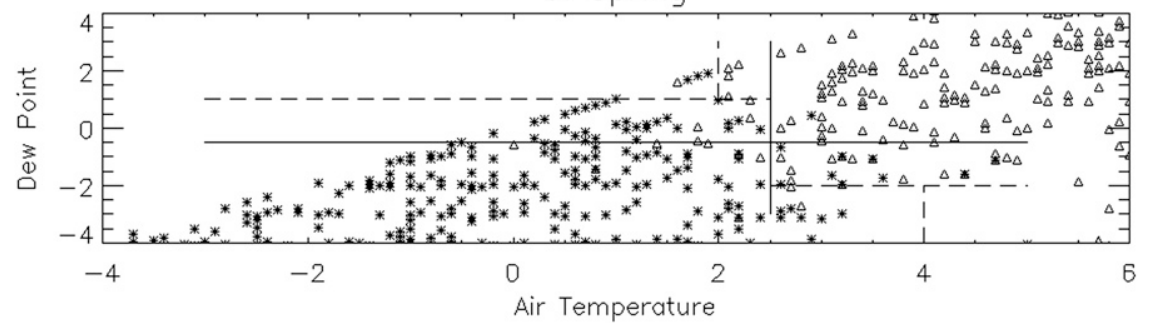

FIG. 10. Solid (star) and liquid (triangle) precipitation corresponding to air temperature and dewpoint when it occurred at a randomly selected station (Ulan-Ude, $51.8^{\circ} \mathrm{N}, 107.43^{\circ} \mathrm{E}$ ) for (a) fall and (b) spring. The horizontal solid line is the CTd, and the vertical solid line is the CT. Horizontal dashed lines are secondary CTds, and vertical dashed lines are secondary CTs.

frequency rises above $50 \%$ in all events that fall into these conditions. In the case of station Ulan-Ude, the secondary CTd (CTd-upper) is $0.5^{\circ} \mathrm{C}$ in the fall (Fig. 10). A similar method determines that the secondary CTd for the lower-right section (CTd-lower) of air temperature greater than $\mathrm{CT}$ and dewpoint less than or equal to CTd is $-2.0^{\circ} \mathrm{C}$ in the fall. After the secondary CTd is determined, the rest of precipitation events that fall either above (upper-left section) or below (lower-right section) are used to determine that secondary CT. Then the secondary critical air temperature from those events that occur at dewpoint greater than CTd-upper and air temperature less than or equal to $\mathrm{CT}$ is derived (called CT-upper; $1{ }^{\circ} \mathrm{C}$ for this station in the fall). Similarly, secondary $\mathrm{CT}$ for the lower-right section of dewpoint less than or equal to secondary CTd and air temperature greater than CT (CT-lower) is $3.5^{\circ} \mathrm{C}$ in the fall. Now, the solid versus liquid precipitation separation is improved with the combination of three CTs and three CTds for each station for spring and fall season separately. In summary, for solid precipitation to occur, there are three combinations of air temperature $(T)$ and dewpoint (Td) conditions: 1) $T \leq \mathrm{TC}$ and Td $\leq$ CTd-upper, 2) $T \leq$ CT-upper, and 3) $T \leq$ CT-lower and $\mathrm{Td} \leq$ CTd-lower. The other conditions will result in liquid precipitation.

When there are not enough sample sizes, especially for the upper-left or lower-right section, the secondary CTs and/or CTds may have the same value as the primary CT or CTd and therefore do not contribute to improve the predictability of the precipitation form. After careful examination of the three CTs and three CTds, we found very few cases of CT-upper and CT-lower equal to primary CT for both spring and fall $(0 \%-2 \%)$, and the situation was similar for CTd-lower (less than 1\%). But for CTd-upper, $168(31 \%)$ stations in spring and $226(41 \%)$ stations in fall have the same value as the primary CTd. This suggests that there is no need for the secondary dewpoint to help separate snow from rain for the upper-left section only.

The results of classified snow and rain events by using various critical CTs and CTds are compared with those observed at all stations. The snow and rain events (black line) and those classified snow and rain events based on the primary CT only (red line), primary CTd only (blue line), and the combination of 3 CTs and 3 CTds (green line) are plotted in Figs. 11a and 11b for fall and spring, respectively. These figures are based on each $0.5^{\circ} \mathrm{C}$ increment of dewpoint temperature for all months studied and all stations. The combination of 3 CTs and CTds correctly predicts $100 \%$ of all snow events when the dewpoint is equal to or below $-0.5^{\circ} \mathrm{C}$, as does primary CT-only prediction, but the primary CTd-only prediction missed some events (Fig. 11a). When dewpoint temperature is higher than $-0.5^{\circ} \mathrm{C}$ and lower than $1.5^{\circ} \mathrm{C}$, the combination of three CTs and three CTds has similar predictability as those using Ctd only. When dewpoint falls above $1.5^{\circ} \mathrm{C}$, the primary CTd-only is the best predictor of snow events. Thus, it seems the combination of using CTs and CTds improves prediction for solid precipitation events most effectively when dewpoint is higher than $-0.5^{\circ} \mathrm{C}$ and lower than $1.5^{\circ} \mathrm{C}$. 

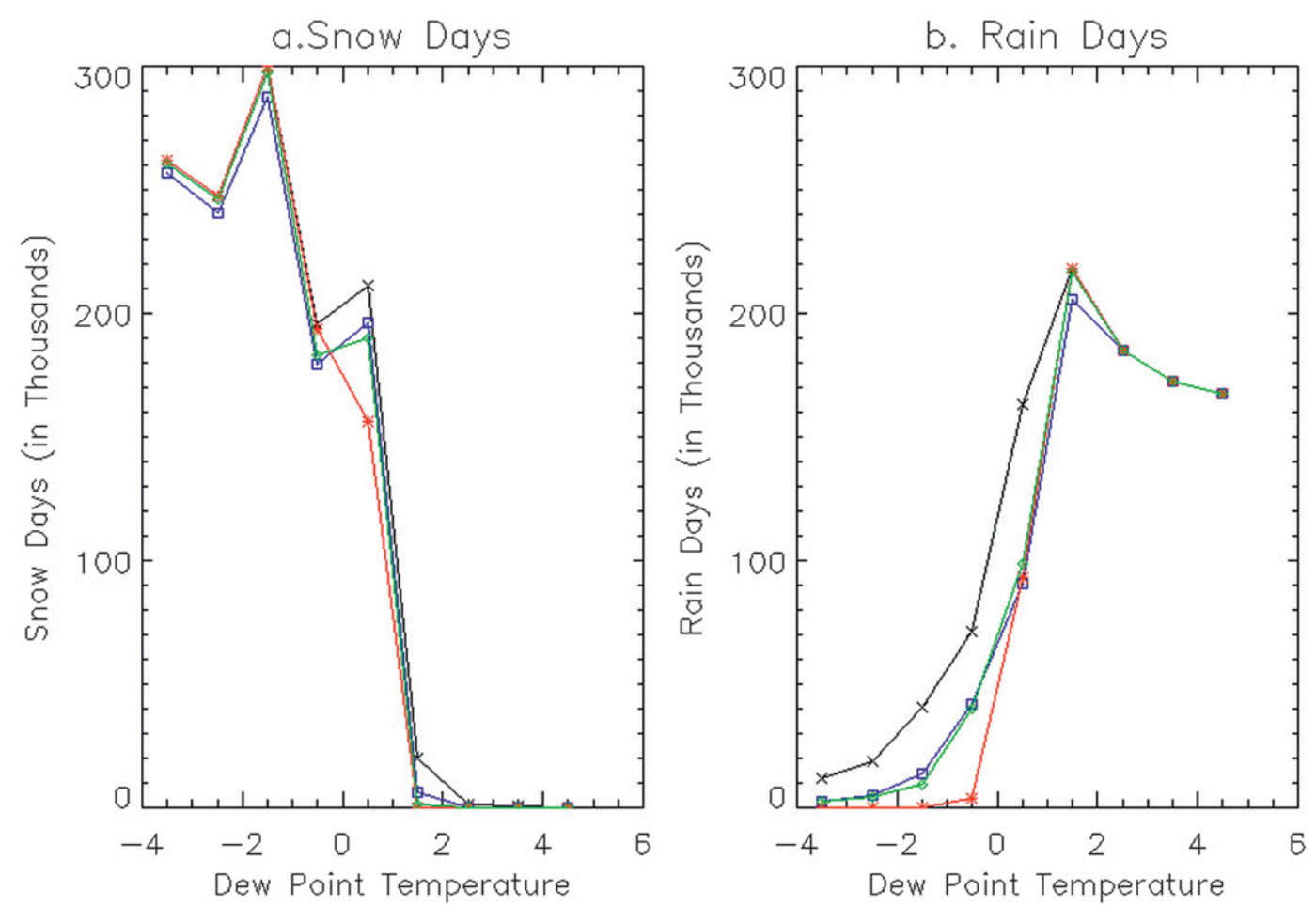

FIG. 11. Observed and predicted precipitation events arranged according to each half-degree increments of dewpoint for all stations and (a) all solid or (b) liquid events. Black line is all solid (or liquid) observed precipitation events, red line is predicted based on CT only, blue line is predicted based on CTd only, and green line is predicted based on a combination of three CTs and three CTds.

For predicting rain events, using the combination of CTs and CTds improves rain prediction when the dewpoint temperature is above $0^{\circ} \mathrm{C}$. When the dewpoint is below that, CTd alone predicts events slightly better, but temperature alone missed many rainfall events (Fig. 11b). For dewpoints higher than $0^{\circ} \mathrm{C}$, using the $\mathrm{CT}$ alone or the combination of CTs and CTds correctly predicted $100 \%$ of rain events, but not when the CTd was the sole predictor. In general, the combination of CTs and CTds improves the prediction for rain events.

\section{d. Future projection}

The geographical distribution of dewpoint and ratio of snow to total precipitation events averaged from the spring and fall seasons are shown in Fig. 12. The mean dewpoint among these 547 stations ranges from $-17.2^{\circ}$ to $10^{\circ} \mathrm{C}$ decreasing toward northern and inland areas (Fig. 12a). A similar distribution pattern of ratio of snow over precipitation events is found, ranging from $2 \%$ to 95\% averaged from both spring and fall (Fig. 12b).

The ratio of snow events to total precipitation events at each station is plotted against the station's mean dewpoint temperature in Fig. 13. It clearly shows that ratio of snow events to total precipitation events decreases with increasing dewpoint in a linear relationship.
A simple regression analyses with ratio as the dependent variable and dewpoint as the independent variable found that the ratio decreases -3.2 per degree of dewpoint increase. The correlation coefficient between the two is -0.9182 , which is statistically significant at 0.01 or above $(N=547)$. The ratio of $50 \%$ snow over total precipitation event corresponds to a mean dewpoint temperature of about $-2.6^{\circ} \mathrm{C}$. This is observable in Fig. 12, where geographical regions of $50 \%$ ratio line seem to roughly corresponding to those of the $-2^{\circ} \mathrm{C}$ dewpoint line.

The projected changes in snow versus total precipitation events will be an across-the-board reduction of about $3.2 \%$ for each dewpoint temperature increase. Climate models predicted a $4^{\circ}-6^{\circ} \mathrm{C}$ increase in air temperature by $2090-99$ over the study region (Trenberth et al. 2007). It is a reasonable assumption that the dewpoint temperature would increase a little more than air temperature given that the relative humidity stays constant (Trenberth et al. 2007). To be conservative, we assume dewpoint temperature increases at similar magnitude if the dewpoint depression stays relatively constant. Using an estimated increase of dewpoint temperature by $4^{\circ} \mathrm{C}$, the ratio of snow to total precipitation events would decrease by more than $12 \%$ in all locales in the study region. 


\section{a. Dew Point Temperature}
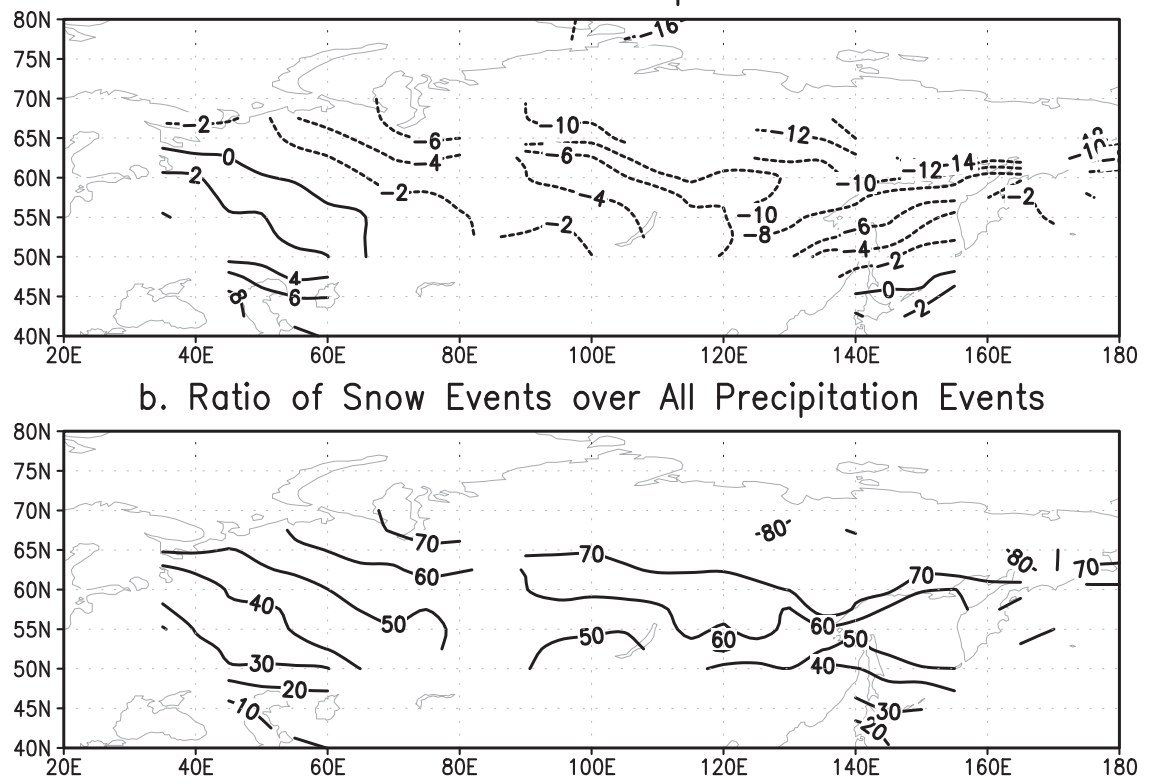

FIG. 12. Geographical distribution of (a) mean dewpoint temperature and (b) ratio of snow events to total precipitation events for both spring and fall seasons combined.

\section{Conclusions}

This study uses historical synoptic observations to define critical thresholds of air temperature and dewpoint that separate solid versus liquid precipitation over northern Eurasia. A total of 547 stations over the period of 1966 through 2000 are evaluated. Results show that critical air temperature that separates solid versus liquid precipitation is geographically and seasonally dependent and influenced by elevation, relative humidity, and station air pressure. Over European Russia, the CTs are around $0.5^{\circ}-1.0^{\circ} \mathrm{C}$ lower than the rest. The highest CTs of $2.0^{\circ}-2.5^{\circ} \mathrm{C}$ are found over south-central Siberia.

Critical dewpoint temperature, however, is less dependent on geographical features and atmospheric conditions, although it occasionally varies with locality, and thus, it is a more representative variable for precipitation phase overall. About $92 \%$ of the stations located in northern Eurasia have critical dewpoint temperatures of $0.5^{\circ}-1.0^{\circ} \mathrm{C}$ (defined as the frequency midpoint of solid versus liquid precipitation). Considering the lack of accuracy in dewpoint records (rounded to the nearest whole number) and the need to derive dewpoint values for this research, our results are quite encouraging.

To further improve the predictability of solid versus liquid precipitation, we recommend using the combinations of three critical air temperatures and three dewpoint temperatures specifically derived for each station. The most significant improvement for event prediction achieved using this combination occurred when dewpoint is higher than $-0.5^{\circ} \mathrm{C}$ and lower than $1.5^{\circ} \mathrm{C}$. When dewpoint is lower than or equal to $-0.5^{\circ} \mathrm{C}$, the use of $\mathrm{CT}$ alone is adequate, and when the dewpoint is $2.5^{\circ} \mathrm{C}$ or above, CTd alone can be applied. For rain events, the combination of critical CT and CTd improves rainfall prediction when dewpoint is higher than or equal to $0^{\circ} \mathrm{C}$. Otherwise, dewpoint alone can be used. The combinations of three CTs and three CTds are included in the supplemental material for use in model simulations of snow accumulation in cold regions.

The ratio of snow events to total precipitation events decreases at a rate of $-3.3 \%$ for each degree of dewpoint

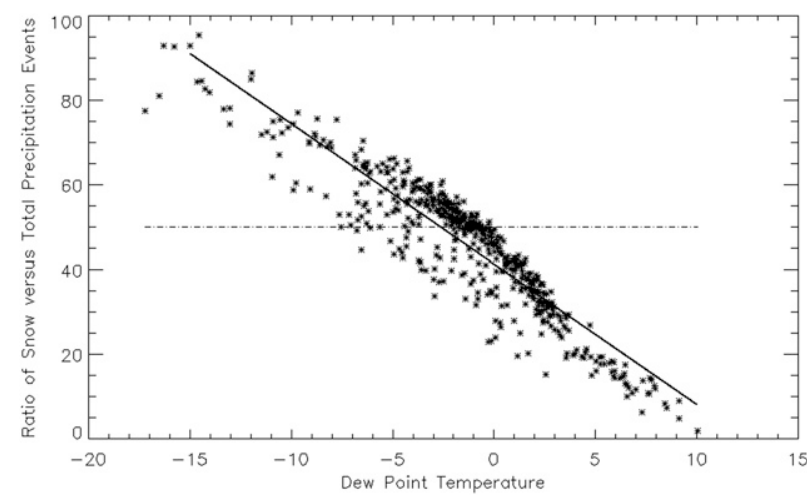

FIG. 13. Scatterplot of each station's ratio of snow events to total precipitation events against the dewpoint temperature. The solid line is the simple linear regression line that represents the computed rate of change. 
increase over the region of study. Using the projection of possible $4^{\circ} \mathrm{C}$ dewpoint temperature increase, the ratio of snow events to total precipitation events would decrease by more than $12 \%$ across the study region in spring and fall.

Acknowledgments. The first author is supported by NSF Grant BCS-1060788, and the second author is supported by NSF Grant BCS-1060323. The first author would like to express her gratitude towards AIRS's Atmosphere group in the Jet Propulsion Laboratory, which allowed her to start this research while her new workstation was in the process of being set up at CSULA during 2011 and 2012. The authors appreciate the three anonymous reviewers' valuable comments that improved the quality of this manuscript.

\section{REFERENCES}

Auer, A. H., 1974: The rain versus snow threshold temperatures. Weatherwise, 27, 67.

Bolton, D., 1980: The computation of equivalent potential temperature. Mon. Wea. Rev., 108, 1046-1053.

Bradley, R. S., F. T. Keimig, and H. F. Diaz, 1992: Climatology of surface-based inversions in the North American Arctic J. Geophys. Res., 97 (D14), 15 699-15712.

Cohen, J., and D. Entekhabi, 1999: Eurasian snow cover variability and northern hemisphere climate predictability. Geophys. Res. Lett., 26, 345-348.

Dai, A., 2008: Temperature and pressure dependence of the rainsnow phase transition over land and ocean. Geophys. Res. Lett., 35, L12802, doi:10.1029/2008GL033295.

Feiccabrino, J., and A. Lundberg, 2008: Precipitation phase discrimination in Sweden. Proc. 65th Eastern Snow Conference, Fairlee, VT, Eastern Snow Conference, 239-254. [Available online at http://www.easternsnow.org/proceedings/2008/ feiccabriono_lundber.pdf.]

Kienzle, S. W., 2008: A new temperature based method to separate rain and snow. Hydrol. Processes, 22, 5067-5085.

Marks, D., and A. Winstral, 2007: Finding the rain/snow transition elevation during storm events in mountain basins. Proc. 24th
General Assembly of the IUGG, Perugia, Italy, IUGG, 652. [Available online at http://www.iugg2007perugia.it/webbook/ pdf/JH.pdf.]

Matsuo, T., Y. Sasyo, and Y. Sato, 1981: Relationship between types of precipitation on the ground and surface meteorological elements. J. Meteor. Soc. Japan, 59, 462-476.

Motoyama, H., 1990: Simulation of seasonal snow cover based on air temperature and precipitation. J. Appl. Meteor., 29, 1104 1110.

NCDC, 2005: National Climatic Data Center data documentation for data set 9290c: Global Synoptic Climatology Network C. The Former USSR, version 1. NCDC, Asheville, NC. [Available online at http://www1.ncdc.noaa.gov/pub/data/ documentlibrary/tddoc/td9290c.pdf.]

Rohrer, M. D., 1989: Determination of the transition air temperature from snow and rain and intensity of precipitation. IAHS/ WMO/ETH International Workshop of Precipitation Measurement, B. Sevruk, Ed., WMO, 475-482.

Serreze, M. C., J. D. Kahl, and R. C. Schnell, 1992: Low-level temperature inversions of the Eurasian Arctic and comparisons with Soviet drifting station data. J. Climate, 5, 615629.

Stull, R., 2000: Meteorology for Scientists and Engineers. 2nd ed. Brooks-Cole, 502 pp.

Trenberth, K. E., and Coauthors, 2007: Observations: Surface and atmospheric climate change. Climate Change 2007: The Physical Science Basis, S. Solomon et al., Eds., Cambridge University Press, 235-336.

U.S. Army Corps of Engineers, 1956: Snow Hydrology: Summary Report of the Snow Investigation. North Pacific Division, USACE, $437 \mathrm{pp}$.

Yang, Z. L., R. E. Dickinson, A. Robock, and K. Y. Vinnikov, 1997: Validation of the snow submodel of the biosphere-atmosphere transfer scheme with Russian snow cover and meteorological observational data. J. Climate, 10, 353-373.

Ye, H., 2003: Changes in transitional snowfall season length in northern Eurasia. Geophys. Res. Lett., 30, 1252, doi:10.1029/ 2003GL016873.

, 2008: Changes in frequency of precipitation types associated with the surface air temperature over northern Eurasia. J. Climate, 21, 729-734.

, D. Yang, and D. Robinson, 2008: Winter rain-on-snow and its association with air temperature in northern Eurasia. Hydrol. Processes, 22, 2728-2736. 